Check for updates

Nuffield Trust, London, UK

john.appleby@nuffieldtrust.org.uk Cite this as: BMJ 2020;370:m3694 http://dx.doi.org/10.1136/bmj.m3694 Published: 30 September 2020

DATA BRIEFING

\title{
Covid-19: A V shaped recovery for the NHS?
}

Ambitious targets have been set, but the ability of the health service to quickly bounce back to pre-covid levels of activity remains in doubt. And is it desirable, asks John Appleby

John Appleby director of research and chief economist

Few would disagree that a sharp ("V shaped," if possible) recovery for the UK economy is desirable. But for the NHS the effect of covid-19 has raised some new (and some old) questions about the care it provides.

As a result of the pandemic the NHS in England has experienced some big changes in the types and especially the volume of work it has been carrying out over the past few months. This was largely a matter of policy as the NHS delayed elective, diagnostic, and other work to create capacity in hospitals for covid-19 cases. In part, too, the huge falls in activity-particularly where there is a significant degree of patient choice such as for accident and emergency treatment-have included decisions by the public not to attend for care.

As the composite chart shows (fig 1), referrals and hospital activity fell across the board. Comparing April 2019 with the lowest point this year (generally April) shows that the number of GP and other referrals plunged by $67 \%$, and elective and emergency admissions by $73 \%$ and $34 \%$, respectively. First attendances at outpatient clinics and A\&E fell by $59 \%$ and $60 \%$, respectively. Diagnostic activity dropped by $68 \%$, and first consultant appointments following an urgent GP referral for suspected cancer fell by $60 \%$. 
- Referrals and hospital activity $\quad$ - - - Waiting list numbers and times
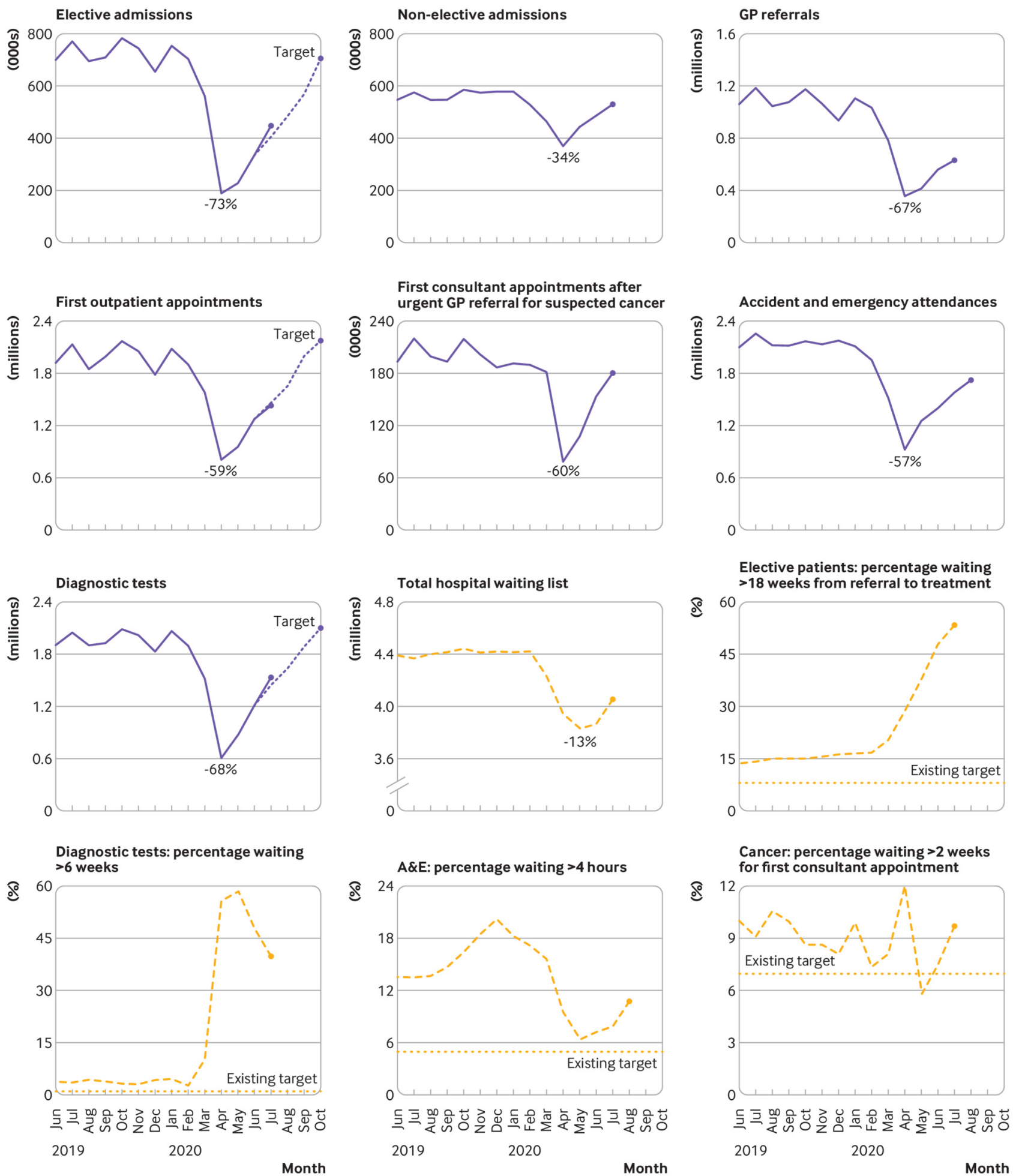

Percentages below curves show lowest point in comparison with April 2019

Fig 1 | Trends in GP referrals, NHS hospital activity and waiting lists and times, England, June 2019 to October $2020^{12}$

So, there are falls in referrals and attendances. But the effect on waiting lists and waiting times has been mixed. The number of patients on elective waiting lists fell as referrals reduced but are now rising as referrals have started to increase again. Waiting times for referral to treatment have not yet returned to pre-covid-19 levels. Waiting times for A\&E and diagnostics rose steeply, and though 
they are now starting to fall, they remain high, with national standards for waiting times comprehensively missed..

But since April's nadir, activity has started to increase as, we must all hope, the covid-19 peak has passed. As with the economy, however, while the broad signs are good (GDP rose in May and June $^{3}$ ), there are significant concerns over the next year and longer. For the economy, that means risks of high and persistent unemployment. ${ }^{4}$ In the NHS, although national leaders have set ambitious targets essentially to get elective admissions, outpatient attendances, and diagnostic activity back to where they were a year ago by October, ${ }^{5}$ it is unclear that such a $\mathrm{V}$ shaped return to normal is either possible or, in some areas, desirable.

With the continuing need for infection control measures in hospitals, the consequent effect on productivity, and recent signs of rising covid cases and hospital admissions, whether it will be possible to return to average levels of pre-covid activity over the next few months must remain in doubt. Inevitably, it would seem, waiting lists and times will grow.

Unless the NHS works harder than before covid-19, the fall in the rate of work between February and April, recovering only by October, will mean a loss of NHS activity over the whole year. For elective care this loss over the nine months from February to October, in comparison with the average level of activity over the previous nine months, would amount to nearly 2.8 million fewer admissions $-38 \%$ of all admissions over the previous, pre-covid, nine months.

Should an alternative post-covid future for healthcare involve learning from the best as well as the worst of this experience, with lower levels of A\&E activity, more remote consultations, greater use of digital technology, and a rethinking of clinical thresholds for treatment and admission?

Competing interests: None declared.

Commissioning and peer review: Commissioned, externally peer reviewed

1 NHS Digital. Provisional monthly hospital episode statistics for admitted patient care, outpatient and accident and emergency data April 2020 - July 2020. 10 Sep 2020. https://digital.nhs.uk/dataand-information/publications/statistical/hospital-episode-statistics-for-admitted-patient-careoutpatient-and-accident-and-emergency-data/april-2020---july-2020.

2 NHS England. Statistical work areas. 2020. https://www.england.nhs.uk/statistics/statisticalwork-areas.

3 Office for National Statistics. GDP monthly estimate, UK: June 2020. 12 Aug 2020. https://www.ons.gov.uk/economy/grossdomesticproductgdp/bulletins/gdpmonthlyestimateuk/june2020.

4 Haldane AG. Speech: the second quarter. Bank of England. 30 Jun 2020. https://www.bankofengland.co.uk/-/media/boe/files/speech/2020/the-second-quarter-speechby-andy-haldane.pdf.

5 NHS England. Letter from Sir Simon Stevens: Important-for action-third phase of NHS response to covid-19. 31 Jul 2020. https://www.england.nhs.uk/Coronavirus/wp-content/uploads/sites/52/2020/07/Phase-3-letter-July-31-2020.pdf.

This article is made freely available for use in accordance with BMJ's website terms and conditions for the duration of the covid-19 pandemic or until otherwise determined by BMJ. You may use, download and print the article for any lawful, non-commercial purpose (including text and data mining) provided that all copyright notices and trade marks are retained. 